\title{
Visual evoked potentials and dietary long chain polyunsaturated fatty acids in preterm infants
}

Giacomo Faldella, Marina Govoni, Rosina Alessandroni, Enrico Marchiani, Gian Paolo Salvioli, Pier Luigi Biagi, Christian Spanò

\begin{abstract}
The influence of dietary long chain polyunsaturated fatty acid (LCP) supply, and especially of docosahexaenoic acid (DHA), on evoked potential maturation, was studied in 58 healthy preterm infants using flash visual evoked potentials (VEPs), flash electroretinography (ERG), and brainstem acoustic evoked potentials (BAEPs) at 52 weeks of postconceptional age. At the same time, the fatty acid composition of red blood cell membranes was examined. The infants were fed on breast milk ( $n=12)$, a preterm formula supplemented with LCP (PF-LCP) $(n=21)$, or a traditional preterm formula $(P F)(n=25)$. In the breast milk and PF-LCP groups the morphology and latencies of the waves that reflect the visual projecting system were similar; in the PF group the morphology was quite different and the wave latencies were significantly longer.

This could mean that the maturation pattern of VEPs in preterm infants who did not receive LCP was slower. Moreover, a higher level of erythrocyte LCP, especially DHA, was found in breast milk and PF-LCP groups compared with the PF group. ERG and BAEP recordings were the same in all three groups.

These results suggest that a well balanced LCP supplement in preterm formulas can positively influence the maturation of visual evoked potentials in preterm infants when breast milk is not available.
\end{abstract}

Istituto Clinico di Pediatria Preventiva e Neonatologia, University of Bologna, Italy

G Faldella

E Marchiani

G P Salvioli

R Alessandroni

Feto-maternal and Developmental

Medicine

M Govoni

Department of

Biochemistry

P L Biagi

C Spanò

Correspondence to:

Professor Giacomo Faldella,

Istituto Clinico di Pediatria

Preventiva e Neonatologia,

Università di Bologna,

Via Massarenti 11,

40138 Bologna,

40138
Italy.

Accepted 9 May 1996 fatty acid precursors. ${ }^{4}$ An LCP supplement, and especially DHA, in preterm formulas improves maturation of rod photoreceptor function and visual acuity in early postnatal development. ${ }^{5-8}$

As far as we know, an evaluation of the influence of infant diet on neurophysiological maturation of flash visual evoked potentials (VEPs) and low rate brainstem acoustic evoked potentials (BAEPs) has never been carried out. We therefore performed a prospective controlled single blind study on preterm infants to evaluate the effect of LCP, either incorporated into the formula or present in breast milk, on the maturation of flash VEPs, flash electroretinography (ERG), and low rate BAEPs. Moreover, we analysed the fatty acid composition in red blood cell membranes as an index of neural and retinal tissue composition.

\section{Methods}

Sixty six preterm infants were enrolled in the study: they were less than 33 weeks of gestational age, of appropriate weight, and with no malformation that could interfere with somatic and/or psychomotor development. They had no neurological, visual, acoustic or gastroenterological illnesses. None had experienced perinatal asphyxia. All of them had normal fundus oculi. By the 10th day of life all of them had received at least $50 \%$ of their caloric requirement through enteral feeding. They were preferentially fed on breast milk whenever available (breast milk, $n=17$ ); otherwise they were randomly assigned to a formula for preterm infants enriched with LCP (Preaptamil with Milupan, Milupa AG, Friedrichsdorf, Germany) (PF-LCP, $n=23$ ), or a traditional formula for preterm infants $(\mathrm{PF}$, $\mathrm{n}=26$ ) (table 1). Infants assigned to the breast milk group received at least $75 \%$ of their own mother's milk. The LCP enriched formula was given to integrate breast milk when necessary. Infants assigned to the formula groups received less than $25 \%$ of their caloric intake from breast milk. These feeding regimens had to be continued until 52 weeks of postconceptional age. At that time 58 infants had remained in their allocated diet group: breast milk, $n=12$ ( 6 of them $100 \%$ breast milk); PF-LCP, $n=21$ (19 of them $100 \%$ formula); $P F, n=25$ (19 of them $100 \%$ formula), and the results refer to them. The three groups were comparable in weight and gestational age (table 2).

Parental informed consent was obtained for each infant before enrolment in the study, and the study was approved by the local ethics committee. 
Table 1 Calorie, protein, and lipid composition of breast milk, LCP supplemented preterm formula (PF-LCP), and traditional preterm formula

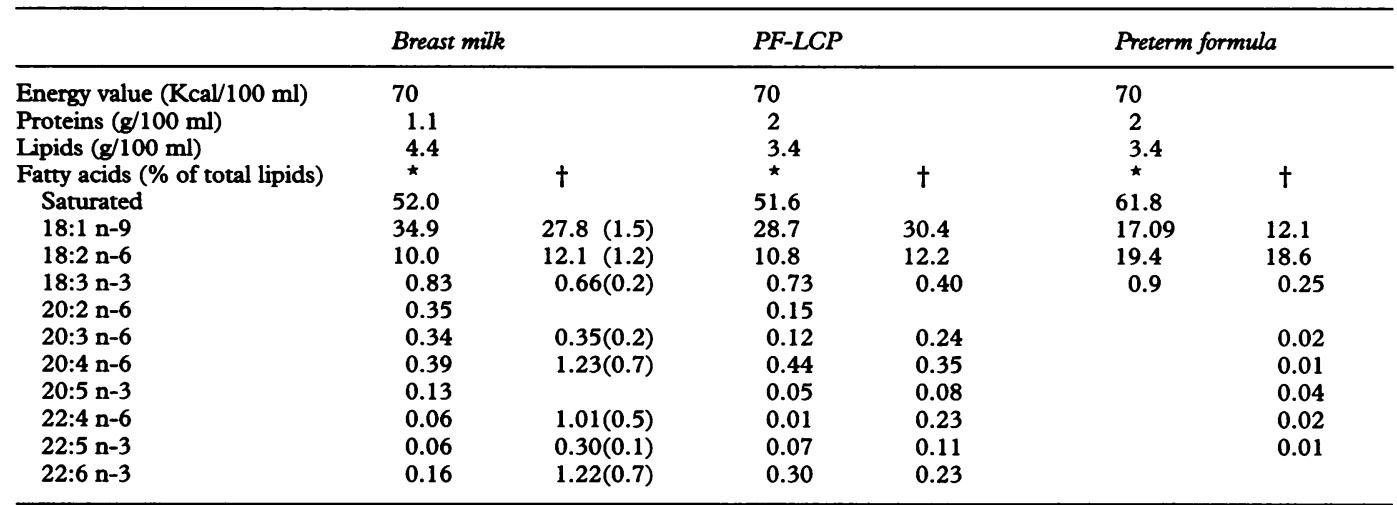

* Data published by the milk company.

† Analysis performed by the research group. Breast milk (SD) from five samples; PF-LCP and preterm formula: one sample.

Table 2 Mean (SD) values of gestational age, birthweight, postnatal growth velocity to age 52 weeks postconception, and erythrocyte membrane LCP at 52 weeks postconception in 58 preterm infants according to diet

\begin{tabular}{lcccc}
\hline & Breast milk $(n=12)$ & $P F-L C P(n=21)$ & Preterm formula $(n=25)$ & $P$ value \\
\hline Gestational age (weeks) & $31.8(1.7)$ & $31.1(1.2)$ & $31.3(1.2)$ & NS \\
Birthweight (g) & $1590(406)$ & $1583(310)$ & $1463(273)$ & NS \\
Weight gain (g/day) & $28.2(4.0)$ & $29.8(5.2)$ & $30.4(5.0)$ & NS \\
Length gain (cm/week) & $0.8(0.1)$ & $0.9(0.1)$ & $0.9(0.1)$ & NS \\
Head circumference gain & $0.6(0.1)$ & $0.6(0.1)$ & $0.6(0.1)$ & NS \\
(cm/week) & $10.4(2.1)$ & $10.1(2.5)$ & $10.0(2.1)$ & NS \\
Arachidonic acid (\%) & $2.4(1.1)$ & $2.5(0.8)$ & $1.3(0.7)$ & 0.0001 \\
DHA (\%) & $29.3(3.4)$ & $30.8(4.3)$ & $33.7(4.6)$ & 0.016 \\
Total $n=6$ (\%) & $3.9(1.5)$ & $3.3(1.1)$ & $2.4(1.1)$ & 0.005 \\
Total $n=3$ (\%) & & & & \\
\hline
\end{tabular}

DHA $=$ docosahexaenoic acid

Growth (weight, length, head circumference) and food tolerance were examined weekly until infants were 40 weeks of postconceptional age, and every two weeks thereafter.

As there were no differences among the diet groups at study entry, we did not analyse the fatty acid composition at that time. In fact, we studied the fatty acid composition of red blood cell membranes during the 52nd week. Lipids were extracted from membranes with cloroform:methanol 2 in 1 , and were methylesterified with methanol/ $\mathrm{HCl} 5 \% \mathrm{v} / \mathrm{v}$ for 1 hour at $70^{\circ} \mathrm{C}$. Gas chromatographic analysis of methyl-esters was performed using a Carlo Erba instrument HRGC 5160 equipped with a fused silicon column SP 2340 (Supelco) of $30 \mathrm{~m} \times 0.32 \mathrm{~mm}$ internal diameter. The temperature column was programmed between $160^{\circ}$ to $210^{\circ} \mathrm{C}$ with a gradient of $8^{\circ} \mathrm{C} /$ minute; the gas carrier He flow was $2 \mathrm{ml} /$ minute. ${ }^{9}$

At 52 weeks of postconceptional age, we tested visual evoked potentials (VEPs), electroretinography (ERGs), and low rate brainstem acoustic evoked potentials (BAEPs). VEPs, ERG, and BAEPs were recorded by an experienced technician using Amplaid MK15 (Ampliphon), and were always examined by the same doctor. Infants were held supine in the mother's arms in a quiet darkened room. Silver disk electrodes were fixed with collodion on the scalp and with plaster on nasion and mastoid, in accordance with the International 10-20 EEG System. ${ }^{10}$ Electrode impedence was lowered to less than $2 \mathrm{kOhm}$ using a saline jelly. Each test was always repeated at least twice and an automatic artefact reject was used. VEPs and ERG were recorded to stimu- late each eye independently. All the records of VEPs were made in a quiet waking state, according to the method of Prechtl and Beintema, ${ }^{11}$ with the infant's eye opened. The stimuli were 100 white flashes delivered by a stroboscope lamp (16 x $7 \mathrm{~cm})$, held $10 \mathrm{~cm}$ in front of patient's eye at the rate of $1 \mathrm{~Hz}$ and at an intensity of 1 Joule. The responses were recorded from an electrode placed on the midline occipital position, referenced to another electrode placed on the midline frontal position over 500 milliseconds. Bandpass was 1-100 Hz. We chose to use Barnet's nomenclature for VEP components ${ }^{12}$; components with similar morphology and latency were given the same label. We considered the latency of all waves except $\mathrm{N} 1$ and $\mathrm{P} 1$. We did not examine the amplitudes as they are reported to be very variable and less useful for clinical evaluation during VEP maturation. ${ }^{13}$

For ERG, the responses to 20 flashes with the same characteristics as mentioned above were recorded from an electrode placed on the bridge of the nose referenced to another electrode placed over the vertex. ${ }^{14}$ The same bandpass as for VEPs and a sweep of 15 milliseconds were used. The latencies of $\alpha$ and $\beta$ waves and $\alpha-\beta$ amplitude were evaluated. For ERG recording, the infants were asleep to avoid muscle artefacts. For ethical reasons no patient was sedated and no mydriatic was used. In order to have the same pupil position during ERG recording infants lay supine with their head held in the axial position and the stroboscope lamp centred on their face.

BAEPs were recorded during spontaneous sleep, from the right (M2) and the left (M1) 
Table 3 Prevalence of well defined waves P3, N4, and P4 of flash VEPs at 52 weeks postconception in three dietary groups

\begin{tabular}{|c|c|c|c|c|}
\hline & Breast milk & $P F-L C P$ & Preterm formula & \multirow[b]{2}{*}{$P$ value } \\
\hline & $n(\%)$ & $n(\%)$ & $n(\%)$ & \\
\hline Eyes examined & 20 & 38 & 30 & \\
\hline P3 & $7(35)$ & $19(50)$ & $24(80)$ & $\begin{array}{l}\mathrm{b}=0.004 \\
\mathrm{c}=0.02 \\
\mathrm{a}=\mathrm{NS}\end{array}$ \\
\hline N4 & $6(30)$ & $14(36.8)$ & $21(70)$ & $\begin{array}{l}\mathrm{b}=0.001 \\
\mathrm{c}=0.001 \\
\mathrm{a}=\mathrm{NS}\end{array}$ \\
\hline P4 & $16(80)$ & $30(78.9)$ & $11(36.7)$ & $\begin{array}{l}b=0.001 \\
c=0.001\end{array}$ \\
\hline
\end{tabular}

$\mathrm{n}=$ Incidence of that wave in the group.

$=$ Breast milk vs PF-LCP.

$\mathrm{b}=$ Breast milk $v s$ preterm formula.

$c=$ PF-LCP vs preterm formula.

mastoids referenced to $\mathrm{Cz}$. Each ear was stimulated independently with low rate clicks $(11 \mathrm{~Hz})$ at the intensity of $100 \mathrm{dBSPL}$, and the other ear was masked with a white sound at the intensity of $60 \mathrm{dBSPL}$. A bandpass of 50-5000 $\mathrm{Hz}$ and a sweep of 15 milliseconds. were used Latencies of I, II, III, IV and V waves were measured, along with I-III, I-V, III-V interpeak latencies.

Some of the infants were sleepy during VEP recording, and as all the infants had to be tested at the same gestational age, we could not repeat the test on another occasion: therefore, they were not included in the final analysis. Thus 44 infants completed the visual evoked potential study (10 breast milk, 19 PF-LCP, 15 PF). Likewise, some subjects were not in the ideal behavioural state during the recording of ERG and BAEPs and so were not included in the analysis: thus ERG was studied in 53 subjects (12 breast milk, 20 PF-LCP, $21 \mathrm{PF}$ ), and BAEPs in 52 infants (11 breast milk, 20 PF-LCP, 21 PF). The evaluation of the evoked potentials was carried out without prior knowledge of the infant's dietary group. The results were then divided into the three dietary groups and analysed statistically.

The statistical analysis was calculated using ANOVA and Student's $t$ test for continuous variables, $\chi^{2}$ test for dichotomous variables, and linear simple regression for correlations. All analysis were made using the Statistical Graphics System, version 6.0.

\section{Results}

Different morphological patterns of flash VEP responses were found in the three dietary groups. Figure 1 shows representative curves from one baby in each group. Early

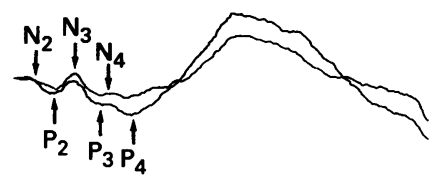

BM

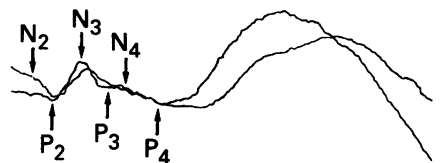

PF-LCP

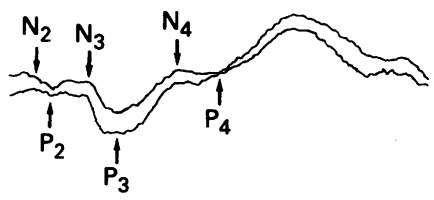

PF

$5 \mu \bar{V} \bar{I}$

$$
50 \text { milliseconds }
$$

500 milliseconds

Figure 1 Morphological patterns of flash VEPs in preterm infants at 52 weeks of postconceptional age, according to diet. Curves refer to one baby from each of the three groups. All the curves have been depicted twice as a measure of repeatability. BM: breast milk; PF-LCP: supplemented preterm formula; PF: traditional preterm formula.

components-that is,waves $\mathrm{N} 2, \mathrm{P} 2$, and N3 whose latencies are less than 100 millijseconds-were present in almost all infants, whereas late component ( $100 \mathrm{msec}$ ) waves $\mathrm{P} 3$, N4, and P4 were not always well identifiable. So the examiner noted down which waves were well defined and which ones were poorly defined or completely absent (table 3 ). In the PF group P3 and N4 waves were mostly well defined, whereas in the breast milk group they were poorly defined or absent for the most part . The infants fed on PF-LCP showed an intermediate waveform that resembled the breast milk rather than the PF group. Wave P4 showed an opposite trend: it was well defined in the breast milk and PF-LCP groups, but poorly defined or absent in the traditional PF group.

Table 4 reports mean values and standard deviations of latencies among the three dietary groups. The latencies of waves N4 and P4 are significantly longer in the PF group than in the PF-LCP and breast milk groups $(P<0.01)$. Moreover, N4 and P4 latencies were similar in breast milk infants and in those fed PF-LCP (not significant). ERG and BAEPs did not reach significance among the three groups (table 5).

While growth parameters did not show any significant difference, the fatty acid composition of red blood cell membranes was different

Table 4 Latencies (milliseconds) of flash VEPs at 52 weeks postconception in three dietary groups

\begin{tabular}{|c|c|c|c|c|c|c|c|}
\hline \multirow[b]{2}{*}{$\begin{array}{l}\text { Latencies: } \\
\text { N2 } \\
\text { P2 } \\
\text { N3 } \\
\text { P3 } \\
\text { N4 } \\
95 \% \text { confidence interval } \\
\text { P4 } \\
95 \% \text { confidence interval }\end{array}$} & \multicolumn{2}{|c|}{ Breast milk (Mean (SD)) } & \multicolumn{2}{|c|}{$P F-L C P(\operatorname{Mean}(S D))$} & \multicolumn{2}{|c|}{ Preterm formula (Mean(SD)) } & P value \\
\hline & $\begin{array}{l}\mathrm{n}=9^{\star} \\
\mathrm{n}=10 \\
\mathrm{n}=10 \\
\mathrm{n}=7 \\
\mathrm{n}=6 \\
\mathrm{n}=9\end{array}$ & $\begin{array}{c}38(4.5) \\
52(7.9) \\
81(8.1) \\
106(7.4) \\
129(15.7) \\
(118-140) \\
174(26.2) \\
(163-185)\end{array}$ & $\begin{array}{l}n=18 \\
n=18 \\
n=19 \\
n=16 \\
n=14 \\
n=17\end{array}$ & $\begin{aligned} & 38(6.6) \\
& 58(9.3) \\
& 84(8.6) \\
& 116(9.5) \\
& 143(17.4) \\
&(136-150) \\
& 178(22.7) \\
&(171-187)\end{aligned}$ & $\begin{array}{l}\mathrm{n}=13 \\
\mathrm{n}=13 \\
\mathrm{n}=15 \\
\mathrm{n}=13 \\
\mathrm{n}=10 \\
\mathrm{n}=12\end{array}$ & $\begin{aligned} 35 & (5.3) \\
53 & (2.9) \\
82 & (9.9) \\
117 & (37.4) \\
171 & (20.8) \\
& (163-180) \\
202 & (19.4) \\
& (193-211)\end{aligned}$ & $\begin{array}{l}\text { NS } \\
\text { NS } \\
\text { NS } \\
\text { NS } \\
\quad 0.0002\end{array}$ \\
\hline
\end{tabular}

* Incidences of that wave group; the numbers refer to the right eyes (maximum: breast milk $=10, \mathrm{PF}-\mathrm{LCP}=19, \mathrm{preterm}$ formula $=15$ ). 
Table 5 Latencies (milliseconds) of BAEPs and latencies and amplitudes ( $\mu V$ ) of ERG at 52 weeks postconception in three dietary groups

\begin{tabular}{lllll}
\hline & $\begin{array}{l}\text { Breast milk } \\
\text { Mean (SD) }\end{array}$ & $\begin{array}{l}\text { PF-LCP } \\
\text { Mean (SD) }\end{array}$ & $\begin{array}{l}\text { Preterm formula } \\
\text { Mean (SD) }\end{array}$ & P value \\
\hline BAEPs & & & & \\
Latencies: & $1.77(0.24)$ & $1.94(0.34)$ & $1.77(0.18)$ & NS \\
$\quad$ I & $2.58(0.33)$ & $2.77(0.29)$ & $2.66(0.16)$ & NS \\
II & $3.26(0.36)$ & $3.47(0.24)$ & $3.36(0.16)$ & NS \\
nII & $4.29(0.37)$ & $4.54(0.36)$ & $4.38(0.22)$ & NS \\
III & $5.23(0.46)$ & $5.48(0.35)$ & $5.29(0.26)$ & NS \\
IV & $6.29(0.38)$ & $6.46(0.37)$ & $6.28(0.26)$ & NS \\
V & $2.52(0.26)$ & $2.60(0.30)$ & $2.61(0.23)$ & NS \\
IPL I-III & $4.52(0.37)$ & $4.52(0.33)$ & $4.51(0.26)$ & NS \\
IPL I-V & $2.00(0.27)$ & $1.92(0.31)$ & $1.90(0.25)$ & NS \\
IPL III-V & & & & \\
ERG & $17.8(1.8)$ & $17.8(1.6)$ & $17.3(2.0)$ & NS \\
Latencies & $49.4(6.8)$ & $49.4(6.4)$ & $47.1(3.0)$ & NS \\
$\quad$ a & $15.5(6.6)$ & $14.8(4.6)$ & $16.0(6.8)$ & NS \\
$\quad$ b & & & &
\end{tabular}

IPL: interpeak latency.

BAEPs: brainstem acoustic evoked potentials.

ERG: flash electroretinogram.
Other studies have shown that the development of the evoked potentials is related to gestational age: the number of waves increases with increasing age and, at the same time, the latency of all components progressively decreases. At two to four months from term, flash VEP morphology is similar to that of an adult, but latencies are longer. ${ }^{13}$ BAEP waveform is complete at 42 to 43 weeks of postconceptional age; the latency maturation reaches values that are similar to an adult's at 18 to 24 months from term. ${ }^{22-23}$

Our data show that not only the age but also the LCP dietary supply influences flash VEP maturation. Even though physiological differences in flash VEP morphology have been described among individuals, ${ }^{13}$ we found a recurrence of three different morphological patterns that correlate with the three dietary regimens. The prevalence of a morphological pattern in the LCP supplemented group, which more closely resembles that of breastfed infants than that of traditional formula fed infants, together with the latency shortness of some late components in the breast milk and PF-LCP groups compared with the PF group, may be the expression of different visual pathway maturation due to different levels of retinal and cerebral LCP. Animal studies have shown that diet-induced changes in the red blood cell membrane fatty acid composition were paralleled by similar changes in the brain and other tissues. ${ }^{24}$ Recently, an association between diet and the fatty acid composition of infant cerebral cortex has been demonstrated. ${ }^{162526}$ The DHA concentration in infant cerebral cortex is greater in breastfed than in traditional formula fed infants, the accretion of cortex DHA being dependent on the length of breast feeding probably because of the supply of preformed DHA. In fact, during early infancy it seems that the brain preferentially uses the preformed long chain polyunsaturated fatty acids and not those synthesised from their precursors. ${ }^{26}$ Makrides et $a l^{25}$ have also demonstrated that infant erythrocyte DHA correlates with that of the brain, indicating that erythrocyte DHA may be a valid indirect marker of cerebral cortex DHA in human infants. In our study the evaluation of the red blood cell membrane composition produced a negative correlation between some VEP late component latencies and the membrane DHA composition. Thus lipid composition in red blood cells reflects the composition of the nervous system membranes, and as DHA particularly concentrates in synaptic membranes, ${ }^{6}{ }^{27}$ these results could mean that the more DHA membrane content there is, the better the synaptic transmission is and the shorter is the wave latency. The influence of dietary LCP on late, but not on early, VEP components at 52 weeks of postconceptional age may be explained on a neuroanatomical basis. The early components, which are related to geniculo-occipital connections (the primary visual system), are already present at birth, mature earlier, and remain more constant in latency compared with the other waves. ${ }^{1328}$ Therefore, diet does not seems to influence them. The late components are the using a low stimulus rate mainly reflect the functional state of brainstem white matter. ${ }^{22}$ 
expression of the more diffusely projecting system (reticulo-cortical or thalamo-cortical connections) that is related to behavioural processes; these interconnections gradually develop, progressively increase in complexity, and mature more slowly than the primary visual system. ${ }^{1328}$ Therefore, the influence of the diet on the late VEP components may be effective for several weeks after birth, especially in preterm newborn infants. Birch et al ${ }^{7}$ did not find any significant difference induced by diet in ERG recorded at 57 weeks of postconceptional age. Our recordings did not show any difference in flash ERG maturation at this age in relation to diet either.

Finally, the lack of any relation between BAEP latencies and both dietary and red blood cell membrane LCP composition suggests little, if any, influence of LCP on the transmission of neuroelectrical signals along the white matter of the brainstem.

In conclusion, our study supports previous findings on the importance of dietary LCP for an optimal visual development of preterm newborn infants. Although long term follow up studies are needed to evaluate the persistence of such an effect at older ages, we believe that a balanced LCP enriched milk formula represents important progress in the early nutrition of preterm infants when mother's milk is not available.

We thank Dr Ada Dormi for help with the statistical analysis.

1 Clandinin MT, Chappell JE, Leong S, Heim T, Swyer PR Chance GW. Intrauterine fatty acid accretion rates in
human brain: implications for fatty acid requirements. human brain: implications for

2 Clandinin MT, Chappell JE, Leong S, Heim T, Swyer PR, Chance GW. Extrauterine fatty acid accretion in brain implications for fatty acid requirements. Early Hum Dev 1980;4:131-8.

3 Dratz EA, Deese AJ. The role of docosahexaenoic acid (22:6 n-3) in biological membranes: Examples from photoceptors and model membranes bilayers. In: Simpoulos AP, ed. Health Effects of Polyunsaturated Fatty Acids in Seafood. New York: Academic Press, 1986:319-51.

4 Decsi T, Koletzko B. Polyunsaturated fatty acids in infant nutrition. Acta Paediatr 1994; suppl 395:31-7.

5 Birch E, Birch D, Hoffman D, Hale L, Evertt M, Uauy R. Breast-feeding and optimal visual development. $\mathcal{f}$ Pediat Ophthalmol Strabismus 1993;30:33-8.

6 Birch EE, Birch DG, Hoffman DR, Uauy R. Dietary essential fatty acid supply and visual acuity development. Invest Ophthalmol Vis Sci 1992;33:3243-53.

7 Birch DG, Birch EE, Hoffman DR, Uauy RD. Retinal development in very-low-birth-weight infants fed diets differing in -3 fatty acids. Invest Ophthalmol Vis $S c$ 1992;33:2365-76.

8 Carison SE, Werkman SH, Rhodes PG, Tolley EA Visual-acuity development in healthy preterm infants: effect of marine-oil supplementation. Am 7 Clin Nutr 1993;58:35-42.

9 Hrelia S, Bordoni A, Celadon M, Turchetto E, Biagi PL Rossi CA. Age-related changes in linoleate and alphalinolenate desaturation by rat liver microsomes. Biochem Biophys Res Commun 1989;163:348-55.

10 Jasper HH. Report of the committee on methods of clinical examination in electroencephalography. Electroenceph Clin Neurophysiol 1958;10:370-5.

11 Prechtl HFR, Beintema DJ. The neurological examination of the full term newborn infants. Clin Dev Med 1964;12:

12 Barnet AB, Friedman SL, Weiss IP, Ohlrich ES, Shanks B, Lodge A. VEP development in infancy and early childhood. A longitudinal study. Electroenceph Clin Neurophysiol 1980;49:476-89.

13 Harden A. Maturation of the visual evoked potentials. In: Chiarenza GA, Papakostopoulos D, eds. Clinical Application of Cerebral Evoked Potentials in Pediatric Medicine. Amsterdam: Excerpta Medica, 1982:41-59.

14 Harden A, Adams GGW, Taylor DS. The electroretinogram. Arch Dis Child 1989;64:1080-7.

15 Anderson RE, Benolken RM, Dudley PA, Landis DJ, Wheeler TG. Polyunsaturated fatty acids of photoceptor Wheeler TG. Polyunsaturated fatty acids
membranes. Exp Eye Res 1974;18: 205-13.

16 Farquharson J, Cockburn F, Ainslie P, Jamieson CE, Logan RW. Infant cerebral cortex phospholipid fatty-acid composition and diet. Lancet 1992;340:810-13.

17 Martinez $M$. Tissue levels of polyunsaturated fatty acids during early human development. $₹$ Pediatr 1992 120:S129-38.

18 Neuringer M, Connor WE. $\omega-3$ fatty acids in the brain and retina:evidence for essentiality. Nutr Rev 1986;44:285-90.

19 Wainwright PE. Do essential fatty acids play a role in brain and behavioural development? Neurosci Biobehav Rev 1992;16:193-205.

20 Uauy-Dagach R, Mena P. Nutritional role of $\omega-3$ fatty acid during the perinatal period. In: Pereira GR, Georgieff MK, eds. Clinics in Perinatology. Philadelphia: WB Saunders Company, 1995:157-75.

21 Taylor M F. Evoked potentials in paediatrics. In: Halliday AM, ed. Evoked Potentials in Clinical Testing. Edinburgh: AMurchill Livingstone, 1993:489-521.

22 Ken-Dror, Pratt H, Zeltzer M, Sujov P, Katzir J, Benderley A. Auditory brain-stem evoked potentials to clicks at different presentation rates: estimating of pre-term and full-term neonates. Electroenceph Clin Neurophysiol 1987, 68:209-18.

23 Goldie DW. The brainstem auditory evoked potentials in infants and children. $\mathcal{f}$ Clin Neurophysiol 1992;9:394-407.

24 Carlson SE, Carver JD, House SG. High fat diets varying in ratios of polyunsaturated to saturated fatty acid and ratios of polyunsaturated to saturated fatty acid and red cell membrane phospholipids. $¥$ Nutr 1986;116:718-26.

25 Makrides M, Neumann MA, Byard RW, Simmer K, Gibson RA. Fatty acid composition of brain, retina and erythrocytes in breast- and formula-fed infants. Am $\mathrm{f}$ Clin Nut 1994;60:189-94.

26 Farquharson J, Jamieson EC, Abbasi KA, Patrick WJA Logan RW, Cockburn F. Effect of diet on the fatty acid composition of the major phospholipids of infant cerebral cortex. Arch Dis Child 1995;72:198-203.

27 Cotman C, Blank ML, Moehl A, Snyder F. Lipid composition of synaptic plasma membranes isolated from rat brain by zonal ultracentrifugation. Biochemistry 1969;8:4606-12

28 Blom JL, Barth PG, Visser SL. The visual evoked potentia in the first six years of life. Electroenceph Clin Neurophysio 1980;48:395-405. 